Research Article

\title{
Innovation and Entrepreneurship Practice Education Mode of Animation Digital Media Major Based on Intelligent Information Collection
}

\author{
Lianlian Liu ${ }^{1}$ and Yongjun Wang $\mathbb{D}^{2}$ \\ ${ }^{1}$ College of Media and Art Design, Guilin University of Aerospace Technology, Guilin 541004, Guangxi, China \\ ${ }^{2}$ School of Electronic Information and Automation, Guilin University of Aerospace Technology, Guilin 541004, Guangxi, China \\ Correspondence should be addressed to Yongjun Wang; dongwang@guat.edu.cn
}

Received 23 June 2021; Revised 12 August 2021; Accepted 17 August 2021; Published 3 September 2021

Academic Editor: Sang-Bing Tsai

Copyright (c) 2021 Lianlian Liu and Yongjun Wang. This is an open access article distributed under the Creative Commons Attribution License, which permits unrestricted use, distribution, and reproduction in any medium, provided the original work is properly cited.

\begin{abstract}
With the rapid development of new media, it has also promoted the transformation of animation expression. One is the change of publishing media, which makes the dissemination of online media work faster and more convenient; the other is the order of magnitude change and the diversity of publishing channels and communication. The choice has contributed to a geometric increase in the number of works published. According to the flow of the new media animation production process, design and establish the classroom situation of animation studios, introduce "work" into the classroom, integrate occupations into studies, highlight occupations in studies, and strengthen professional concepts in the courses, in the form of animation studios, combined with animation companies. The production process and assessment standards effectively organize students to actively master animation theory knowledge and production technology; these experiences can accumulate effective and valuable experience for students' career development. This article mainly introduces the research on the innovative and entrepreneurial practice education model of animation digital media major based on intelligent information collection and intends to provide some ideas and directions for the innovation and entrepreneurship practice education model reform of animation digital media major. This article proposes a studio-based animation digital media professional innovation and entrepreneurship practice education model research methods, used for studio-based animation research and experiment on innovation and entrepreneurship practice education mode of digital media major. The experimental results of this paper show that the Cronbach's $\alpha$ coefficients of the questionnaire are all greater than 0.8 , indicating that the survey content of the questionnaire is more authentic and highly reliable.
\end{abstract}

\section{Introduction}

With the steady and rapid development of the socialist economy, the country's demand for innovative talents is becoming increasingly tense. Innovation and entrepreneurship education is essentially a kind of practical training. At this stage, it is very necessary to carry out research on university innovation and entrepreneurship education. It mainly involves students' entrepreneurship and employment, training professional students' innovative practical skills, and building innovative cities and countries. Under such circumstances, universities must recognize the value and importance of innovation and entrepreneurship education in national and social development. To this end, schools should strive to create conditions to create an education model suitable for training innovators and entrepreneurs and improve students' entrepreneurial skills and entrepreneurial spirit. Finally, comprehensively enhance the country's innovation capabilities, realize the Chinese dream, and realize the great rejuvenation of the Chinese nation.

With the continuous development of culture and economy, the market needs more and more design talents who can quickly adapt to social development. In animation and digital media, the training of talents must also be multilevel and diversified. For now, the traditional digital media education model has been unable to adapt to the 
development of the market. How to adapt to the development of society and reform the existing education model has become the focus of attention. Creating an animation digital media professional intelligent information collection teaching model will be a favorable way to further develop large-scale digital animation media. Studying the teaching mode of the animation digital media professional studio system can not only promote the sustainable development of the entire art education, but also promote the reasonable operation of the animation digital media innovation and entrepreneurship practice education, which has certain practical significance for future development.

Wang survey found that art design disciplines are becoming very popular nowadays. Due to the rapid growth of various industries, the demand for design talents is increasing. How to combine theory with practice and cultivate excellent art design talents has become the focus of art design teaching. For this reason, taking into account the actual development of the university, Wang introduced the theoretical knowledge of intelligent information collection into the basic teaching of art design discipline and found out the problems in the application; secondly, he adopted the analytic hierarchy model and evaluation index system to target. The rules and evaluation objects are analyzed; then through peer evaluation and student evaluation, a judgment matrix is established; finally, the relevant research results are verified through algorithms. This research step is relatively clear but lacks experimental data support and is not persuasive [1]. Zhou believes that, with the popularization of higher education, the traditional single-disciplinary training model can no longer adapt to the ever-changing situation, which requires colleges and universities to transform the traditional training model into an innovative and entrepreneurial model. Through the efforts of domestic colleges and universities to improve the theoretical system of entrepreneurship education, it can provide direction guidance and talent training for innovation and entrepreneurship education and briefly introduce the role of colleges and universities in innovation and entrepreneurship education. Zhou proposed that students should be based on the differences in innovation and entrepreneurship abilities to build a hierarchical education model. Zhou believes that, under this circumstance, colleges and universities can recognize their role in innovation and entrepreneurship education and build a suitable innovation and entrepreneurship education model, which is of great significance to the promotion of higher education teaching reform and can also cultivate students' entrepreneurial ability and practice ability to realize relevant teaching reforms. The theoretical basis of this method is relatively good, but it has not been applied in experiments and lacks scientificity [2]. Clarke and Hulbert believe that art education provides students with opportunities to acquire knowledge and skills, while art design students need to cultivate the creativity of knowledge, thinking, and behavior in the intelligent information collection to promote social construction, material sensitivity, and conceptual concepts of exploration. Clarke and Hulbert discussed a two-year major change plan, which was implemented in the Australian urban art school. It considered ways to address the compliance and survivability requirements of the intelligent information collection education model, while maintaining the idea of how to cultivate the profound value of creativity of undergraduates; by treating the study and curriculum design of animation digital media as a creative process, this initiative of change has reimagined an epistemological framework for college art design teaching; it will maintain the fruits of creative education in the future. This research process has a long time span and is not practical [3].

The innovations of this article are (1) proposing the use of analytic hierarchy process to evaluate the effect of education reform; (2) proposing relevant measures for the operation of the animation digital media professional intelligent information collection; and (3) conducting animation based on the intelligent information collection innovation and entrepreneurship practice education model reform design for digital media majors.

\section{Method of Creative and Entrepreneurship Practice Education Mode for Animation Digital Media Major Based on Intelligent Information Collection}

\subsection{Method}

2.1.1. Document Retrieval Method. Retrieving a large number of documents through network data resource websites such as CNKI, Wanfang Data, Duxiu, SpringerLink, and Baidu Academic is done to classify, summarize, analyze, and check the teaching reform of animation digital media under the concept of innovation and entrepreneurship practice education in recent years. The development profile, knowledge requirements, and training models of the company are used to carefully study the training programs of excellent colleges and then consult the historical evolution and current status of the animation digital media teaching reform under the innovative and entrepreneurial education concept in the foreign literature and learn from relevant experience for research on the studio-based animation and digital media professional innovation and entrepreneurship practice education model to provide primary and basic theoretical support $[4,5]$.

2.1.2. Expert Interview Method. According to the research direction of this article, through interviews with university art teachers, art teaching, and other related fields of experts and scholars, analysis, and discussion of the role of studio teaching in university animation teaching, carefully listen to expert opinions and adopt them as appropriate [6]. Provide multiple perspectives to promote the research of this paper and provide more realistic basis for the paper. Before each interview, the interview outline and required materials will be fully prepared to ensure the smooth progress of the interview and the actual achievement of the expected purpose [7]. The main content of the interview covers the current development of university art education based on intelligent information collection teaching reform and the teaching 
problems and obstacles in the teaching process of animation digital media based on intelligent information collection, as well as the university's understanding of animation digital media in the information age and reform measures, etc. It provides more sufficient guarantee for the discussion and research of the promotion and development of art design teaching based on intelligent information collection in universities [8].

2.1.3. Questionnaire Survey Method. Drawing on the traditional questionnaire survey method, we have initially grasped the first-hand data of the studio-based animation and digital media professional innovation and entrepreneurship practical education model research and evaluated the data from each selection. Starting from the analysis, we have a comprehensive understanding of the needs and suggestions of current college students majoring in animation digital media and in-depth analysis of the value orientation of data, so as to provide reference for the next step to find out the problems and causes of the animation digital media major's teaching mode [9]. After the questionnaire survey is over, the reliability of the questionnaire is tested. For example, after a few weeks, the questionnaire survey is conducted again, and the basic condition of students after class and the correlation coefficient measured before and after the satisfaction degree problem are calculated by SPSS17.0 statistical software [10].

2.2. Teaching Effect Evaluation Algorithm of Intelligent Information Collection: AHP. Analytic hierarchy process (AHP) was proposed by Saaty Th.L. in the 1970s and is a typical application of decision-making evaluation systems in reality [11]. The decision-making evaluation system is a clear, scientific, and reasonable decision-making reference for a project or project development and an objective and democratic evaluation of the operation of a project. In this system, it is mainly to make a reasonable evaluation of the index system structure of the evaluation system and determine the weight of the index [12].

2.2.1. Construction of a Pairwise Comparison Matrix. Establish a pairwise comparison judgment matrix and use $B_{i j}$ to indicate the importance of $B_{i}$ relative to $B_{j}$. A total of $n(n-1) / 2$ comparisons are required $[9,13]$. According to the properties of the consistent positive and negative matrix, a complete judgment matrix can be constructed as

$$
\begin{aligned}
& B=\left[\begin{array}{cccc}
b_{11} & b_{12} & \cdots & b_{n} \\
b_{21} & b_{22} & \cdots & b_{2 n} \\
\vdots & \vdots & \vdots & \vdots \\
b_{n 1} & b_{n 2} & \cdots & b_{n n}
\end{array}\right]=\left(b_{i j}\right)_{n \times n}, \\
& b_{i j}=\frac{b_{l j}}{b_{l i}}, \quad i, j=1,2, \ldots, n .
\end{aligned}
$$

2.2.2. Calculation of Single-Level Weight Ranking. The judgment matrix only gives the degree of relative importance of certain indexes in the upper layer and certain indexes in the next layer [14]. Hierarchical single-weight sorting refers to calculating the importance of certain indexes of the next layer to the related indexes of the previous layer according to the judgment matrix, that is, the weight value. It is also the basis for ranking the importance of all indicators at this level relative to the indicators at the previous level [15].

Normalize the number of elements in each row of the judgment matrix:

$$
\overline{b_{i j}}=\frac{b_{i j}}{\sum_{k=I}^{n} b_{k j}}, \quad i, j=1,2, \ldots, n .
$$

Add the normalized judgment matrix $B$ in rows:

$$
\begin{aligned}
\overline{W_{i}} & =\frac{\overline{W_{i}}}{\sum_{j=1}^{n} \overline{W_{j}}}, \quad i=1,2, \ldots, n, \\
\overline{W_{i}} & =\left(\overline{W_{1}}, \overline{W_{2}}, \ldots, \overline{W_{n}}\right) .
\end{aligned}
$$

Normalize the vector $\bar{W}$ :

$$
W_{i}=\frac{\overline{W_{i}}}{\sum_{j=1}^{n} \overline{W_{j}}}, \ldots i=1,2, \ldots, n .
$$

Then the feature vector is

$$
W=\left(W_{1}, W_{2}, \ldots, W_{n}\right)^{T} .
$$

Calculate the largest characteristic root of judgment matrix $B$ :

$$
\lambda_{\max }=\frac{1}{n} \sum_{i=1}^{n} \frac{(B W)_{i}}{W_{i}} .
$$

If $B$ is a consistent matrix, then there is

$$
\begin{aligned}
\lambda_{\max } & =n, \\
b_{i k} \times b_{k j} & =b_{i j} .
\end{aligned}
$$

In order to test the consistency of the judgment matrix $B$, it is necessary to calculate its consistency index CI:

$$
\mathrm{CI}=\frac{\lambda_{\max }-n}{n-1} \text {. }
$$

The consistency ratio has the following relationship:

$$
\mathrm{CR}=\frac{\mathrm{CI}}{\mathrm{RI}}<0.1 .
$$

At this time, it is considered that the judgment matrix has satisfactory consistency, and $W$ can be used as the weight of a certain index of the previous layer to which certain indexes of the next layer are related. Otherwise, experts must be asked to reconstruct or adjust the judgment matrix $B$, and then calculate the maximum characteristic root $\lambda_{\max }$ of the judgment matrix $B$ until the consistency requirement is met [16]. The subindex judgment matrix $B$ and ranking weight $W$ of other indicators are calculated in the same way until all 
subindex judgment matrix $B$ and ranking weight $W$ in the decision evaluation system ladder model are processed $[17,18]$.

The method part of this article uses the above method to study the creative and entrepreneurial practice education mode of animation and digital media specialty based on the studio system. The specific process is shown in Figure 1.

\section{Experiment on the Innovation and Entrepreneurship Practice Education Mode of Animation Digital Media Specialty Based on Intelligent Information Collection}

3.1. Reform Design of Creative and Entrepreneurship Practice Education Model for Animation Digital Media Major Based on Intelligent Information Collection. The practical education model based on intelligent information collection is the basic carrier to realize the three functions of education and teaching, academic research, and social service. With the three major functions of education and teaching, academic research, and social service of the college highlighted, the intelligent information collection is the most ideal teaching platform to realize the above three functions. And it can effectively stimulate the teachers' team consciousness and personality characteristics, which is in line with the characteristics of the professional development of animation digital media [19].

\subsubsection{Function of Practical Education Model Based on In-} telligent Information Collection. The intelligent information collection should undertake the work of teaching students and be responsible for the related professional teaching curriculum, curriculum content design, textbook compilation, teaching reform research, and other work [20].

The intelligent information collection shall preside over scientific research and creation tasks and be responsible for scientific research and creation tasks in related disciplines, such as topics, writings, papers, creation and design, etc. $[21,22]$.

The intelligent information collection should also exhibit social service activities and be responsible for carrying out horizontal cooperation projects in related disciplines or professional directions with local governments at all levels, enterprises and institutions, and social and cultural groups [23].

\subsubsection{Personnel Composition of Practical Education Model} Based on Intelligent Information Collection. The professional practical education mode of animation and digital media based on intelligent information collection is mainly composed of moderators, tutor groups, and teacher groups. Among them, the host is responsible for the overall work of the studio and proposes the intelligent information collection training plan and teaching plan. He must have a systematic conception of the studio's teaching, scientific research, and service and be able to independently preside over the teaching, scientific research, and service work and have a strong organization, coordination, and communication skills; the tutor group presides over the studio's related courses, textbooks, and equipment construction plans and is responsible for demonstrating the relationship between course objectives, course content, and courses, selecting social service content, and undertaking postgraduate teaching work; the faculty consists of the school. The team of teachers and external teachers is responsible for the course teaching, textbook compilation, and practical guidance of the studio, as well as social service work $[24,25]$.

3.1.3. Optimizing the Curriculum. Professional curriculum construction is the basic construction of university education and teaching and is the central link to improve teaching quality. Combined with the reform of intelligent information collection teaching methods, the existing basic digital media curriculum structure has been optimized. And try to formulate a curriculum with a logical structure and specific characteristics and meet the needs of social development [26]. To study how to transform the curriculum from a traditional classroom system to an intelligent information collection, we must not only pay attention to the topics it focuses on, but also pay attention to training in practical arts, expressive arts, comprehensive arts, and humanities; we should pay attention to training a relatively wide range of art subject knowledge; at the same time, we should take into account the development of students' unique aesthetic personality needs [27].

3.1.4. Adjusting the Teaching Management Organization System. The university needs to change the administrative system of the original teaching and research section and establish a three-level management system of college, department (department), and studio, namely, college-department (department-) studio, establishing a chain of intelligent information collection teaching mode, management operating mode [2]. All links are intertwined, highlighting their own characteristics, and highlighting the principles of teaching management with clear responsibilities, keeping each other's operations smooth. After adjustment and reform, the work cohesion of teaching operation has been significantly enhanced, and the overall teaching quality has been improved [28].

3.1.5. Construction of Digital Management Platform. For the operation of the intelligent information collection teaching mode, the college can develop and improve the digital teaching management platform with the help of computer network technology and multimedia information technology. The digital management platform has the functions of teaching management, teaching resource library construction, teaching knowledge responsibility, and teaching evaluation, which can effectively save costs and improve the operating efficiency of the studio. 


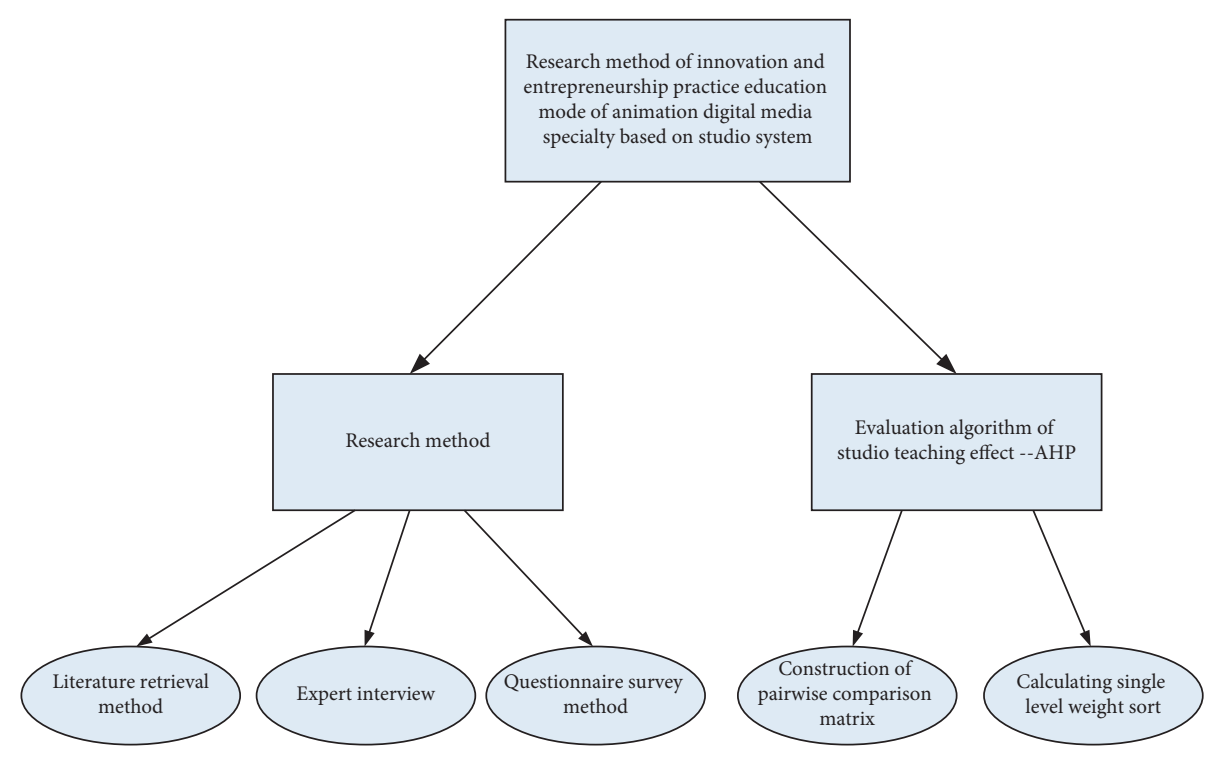

Figure 1: Part of the technical process of this method.

\subsection{Related Measures for the Operation of Animation Digital Media Professional Intelligent Information Collection}

\subsubsection{Training High-Tech, High-Content, and High-Quality} Talents. Under the management of the intelligent information collection teaching model, students can continuously improve the application of software based on some practical cases, so as to improve students' high-tech training; according to the teaching method combining theory and practice, let students be familiar with animation production. In order to improve the training of students' knowledge content, on the platform of the studio, the high quality of students is not only good learning and good people, but more importantly, let students realize that they are in this environment having a team spirit and a serious attitude towards things, such as using the mutual cooperation between each student to continuously improve the overall quality.

\subsubsection{Cultivating Talents with Strong Professional Practical} Operation Ability. In terms of curriculum and teaching methods, the curriculum of this major should be adapted to the needs of the society as the goal, highlighting its practicality. In terms of teaching methods, practical project teaching methods can be used as the main method to apply traditional theoretical knowledge teaching to each practical operation process and use practice to strengthen theoretical knowledge, so as to apply what has been learned; in the training base inside and outside the school, in terms of construction, the construction of the on-campus training base will help students to provide a simulated training environment on the basis of professional content learning, which will invisibly strengthen the learning of professional skills.

3.2.3. Strengthening Teacher Training and Improve the Level of Teachers. The teaching method of the intelligent information collection also puts forward higher requirements on the overall level of teachers. Teachers must not only have a high-quality animation production level, but also have rich social practical experience and strong communication skills with the outside world. Improving the overall level of lecturers will help improve the professional level of students.

3.2.4. Developing Teaching Methods according to Individual Conditions. The teaching method of the intelligent information collection is an inevitable trend in the development of the university's animation and digital media major. The local culture, economic development level, living customs, and other social issues should be studied, and intelligent information collection teaching should be carried out according to the conditions of the digital media professional. There must be sufficient research, analysis, and discussion. At the same time, we must combine our own educational resources and specific conditions to fully study and understand the drawbacks and shortcomings of the old teaching mechanism and strive to make full use of the advantages and disadvantages of the new teaching mechanism, effectively solve the contradictions between the advantages and disadvantages of the new operating mechanism, and realize the development of the new teaching mechanism.

This part of the experiment proposes that the above steps are used in the research experiment of the creative and entrepreneurial practice education mode of animation digital media specialty based on intelligent information collection. The specific process is shown in Table 1.

\section{Innovation and Entrepreneurship Practice Education Mode of Animation Digital Media Major Based on Intelligent Information Collection}

4.1. Survey Object Analysis. This questionnaire survey adopts the "Questionnaire Star" questionnaire survey platform. 
TABle 1: Some steps of this experiment.

\begin{tabular}{|c|c|c|c|}
\hline \multicolumn{4}{|c|}{$\begin{array}{c}\text { Research and experiment on the innovation and entrepreneurship practice education mode of animation digital media specialty based on } \\
\text { studio system }\end{array}$} \\
\hline 3.1 & $\begin{array}{l}\text { Reform design of creative and entrepreneurship practice education model } \\
\text { for animation digital media major based on studio system }\end{array}$ & 3.2 & $\begin{array}{l}\text { Related measures for the operation of an } \\
\text { digital media professional studio sys }\end{array}$ \\
\hline 1 & Studio & 1 & $\begin{array}{c}\text { Cultivate high-tech, high-content, and high-quality } \\
\text { talents }\end{array}$ \\
\hline 2 & Studio & 2 & Cultivating talents wi \\
\hline 3 & Optimi & 3 & $\begin{array}{r}\text { Strengthen teacher training an } \\
\text { level }\end{array}$ \\
\hline 4 & $\begin{array}{l}\text { Adjust the teaching } \mathrm{n} \\
\text { Digital managen }\end{array}$ & 4 & $\begin{array}{c}\text { Develop teaching methods according to individual } \\
\text { conditions }\end{array}$ \\
\hline
\end{tabular}

Questionnaire Star is a professional online questionnaire survey, statistics, and analysis platform that can provide users with complete functions such as questionnaire design, questionnaire distribution, questionnaire recovery, and survey result analysis. Compared with traditional questionnaire surveys, Questionnaire Star has the advantages of accurate data, high credibility, convenient operation, and complete statistical functions, so it is widely used in university research and surveys. The questionnaire survey adopted an online random sampling survey method. A total of 621 questionnaires were distributed to college students majoring in animation and digital media, and 617 valid questionnaires were collected, with a questionnaire efficiency of $99.36 \%$.

(1) Sort out the collected valid questionnaire results, and analyze the running levels of the sample universities. The specific situation is shown in Table 2 and Figure 2.

In this questionnaire, provincial undergraduate colleges and universities participated in the survey the most, followed by ministerial colleges and universities, followed by "double first-rate" colleges and universities, and " 211 project" colleges and universities the least. The survey results show that the sample universities have a certain degree of representativeness, and the survey results obtained can reflect to a certain extent the current reality of the university's animation and digital media professional intelligent information collection innovation practice education, and the data obtained can meet the requirements of research and analysis.

(2) The subjects of this questionnaire are college students majoring in animation and digital media. A total of 617 students participated in the survey. From freshman to senior year, boys to girls, all participated in the survey. The specific distribution is shown in Table 3 and Figure 3.

It can be seen from the chart that the selection of research objects is relatively average, the gap between the total number of university students selected for freshmen, sophomore, junior, and senior is small, and the gap between the number of male and female students selected for the four grades is also small.
TABLE 2: Levels of the sample universities.

\begin{tabular}{lcc}
\hline School level & $\begin{array}{c}\text { Number of } \\
\text { schools }\end{array}$ & Percentage \\
\hline "985 project" colleges & 4 & 13.79 \\
"211 project" colleges & 3 & 10.34 \\
"Double first-class" university & 5 & 17.24 \\
project & 6 & 20.69 \\
Undergraduate colleges & 7 & 24.14 \\
Provincial undergraduate colleges & 4 & 14.80 \\
Vocational colleges & 29 & 100 \\
Total & & \\
\hline
\end{tabular}

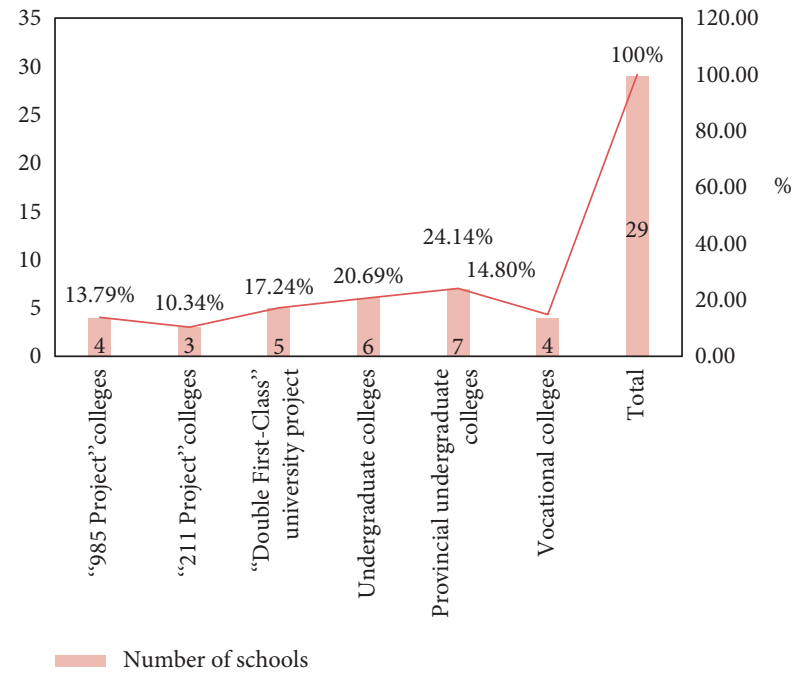

FIGURE 2: The level of running the sample universities.

TABle 3: Distribution of students participating in the questionnaire.

\begin{tabular}{lcccc}
\hline Sex & Freshman & Sophomore & Junior & Senior \\
\hline Boys & 75 & 72 & 77 & 71 \\
Girls & 86 & 85 & 76 & 75 \\
Total & 161 & 157 & 153 & 146 \\
\hline
\end{tabular}

This makes the experimental data more convincing and the experimental conclusions more representative. 


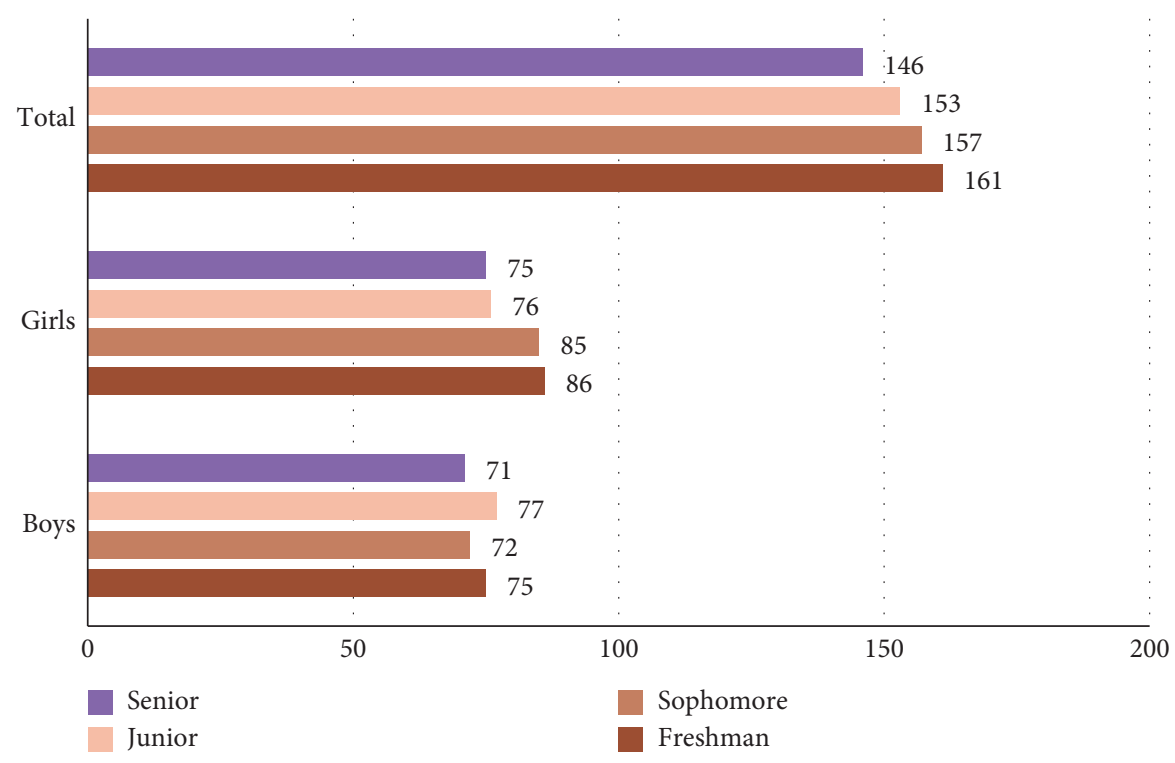

FIgURE 3: Distribution of students participating in the questionnaire.

TABle 4: Attitudes of students to the studio teaching model.

\begin{tabular}{|c|c|c|c|c|c|c|c|c|c|}
\hline & \multirow{2}{*}{ Option } & \multicolumn{2}{|c|}{ Freshman } & \multicolumn{2}{|c|}{ Sophomore } & \multicolumn{2}{|c|}{ Junior } & \multicolumn{2}{|c|}{ Senior } \\
\hline & & Boys & Girls & Boys & Girls & Boys & Girls & Boys & Girls \\
\hline 1 & I really like the studio teaching model & 34 & 28 & 41 & 48 & 37 & 36 & 43 & 45 \\
\hline 2 & Hope that the studio teaching model can be popularized to other courses & 26 & 38 & 22 & 24 & 31 & 35 & 22 & 27 \\
\hline 3 & Indifferent & 13 & 17 & 8 & 11 & 7 & 4 & 5 & 2 \\
\hline 4 & Not quite accepting the studio teaching model & 2 & 3 & 1 & 2 & 2 & 1 & 1 & 1 \\
\hline 5 & Total & 75 & 86 & 72 & 85 & 77 & 76 & 71 & 75 \\
\hline
\end{tabular}

\subsection{Survey Results}

(1) This research has set up the questionnaire about the recognition attitude of college students towards the smart sports classroom teaching mode, which is divided into the following four options (each student can only choose one): (1) I like the intelligent information collection teaching mode very much; (2) I hope that the intelligent information collection teaching model can be popularized to other courses; (3) it does not matter; and (4) the intelligent information collection teaching model is not acceptable. Statistically organize the results of the questionnaire and plot the specific situation into a chart, as shown in Table 4 and Figure 4.

It can be seen from the chart that most students from freshman to senior year choose "very much like the intelligent information collection teaching model"; the second choice is "hope that the intelligent information collection teaching model can be popularized to other courses." The person who chose the third place was "it does not matter"; the person who chose the least number was "do not accept the intelligent information collection teaching model." This shows that the majority of students majoring in animation and digital media recognize the studiobased teaching model.

(2) During the interview, this research asked forty university animation and digital media teachers about their views and opinions on the studio-based animation and digital media innovation and entrepreneurship practice education model, as shown in Table 5 and Figure 5.

The university's animation and digital media teachers generally support the innovation and entrepreneurship practice education reform of the major and believe that the education reform and innovation are conducive to better learning and practice for students.

(3) In order to ensure the feasibility of each item in the entire questionnaire, a total of 25 experts and scholars in the field of animation and digital media teaching were asked for help, and the content of the questionnaire was qualitatively evaluated. It mainly evaluates the four aspects of questionnaire design, questionnaire structure, questionnaire content, and questionnaire logic. The evaluation indicators are set to five levels: very reasonable, reasonable, basically reasonable, unreasonable, and fundamentally 


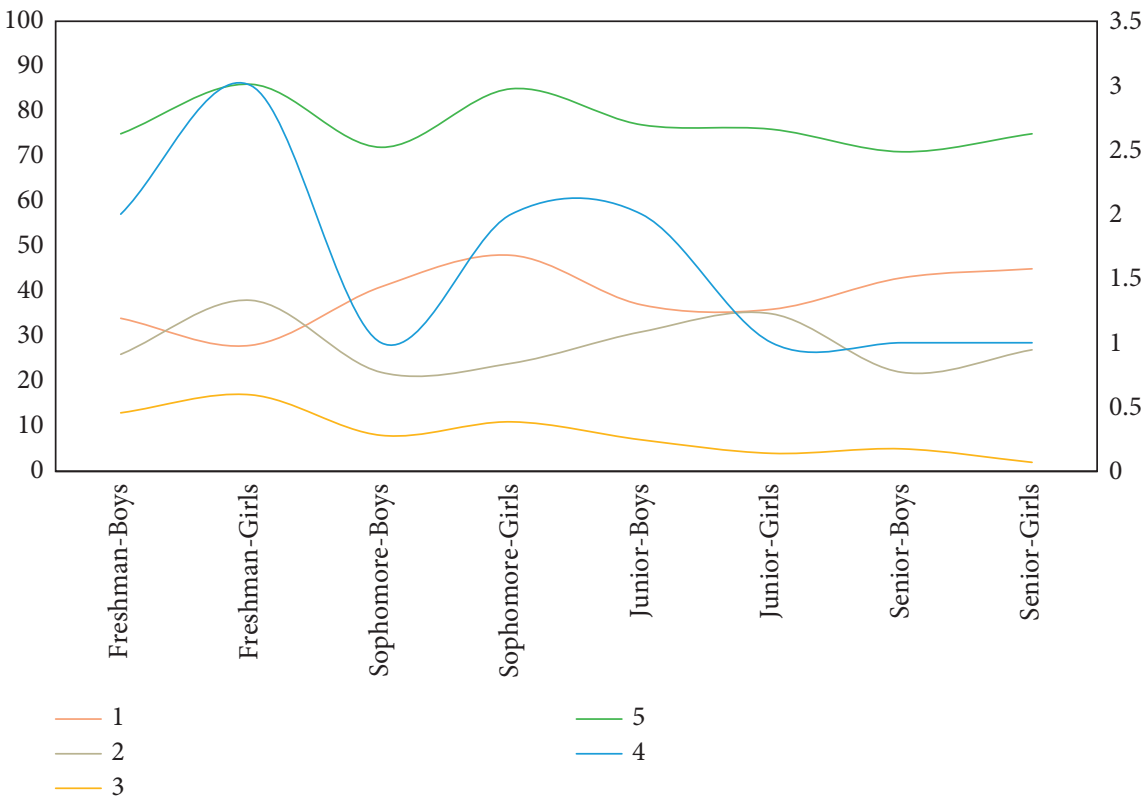

FIgURE 4: Students' recognition attitude towards the studio teaching model.

Table 5: Teacher opinion.

\begin{tabular}{lccc}
\hline & Opinion & Number of teachers & Percentage \\
\hline 1 & Can improve student motivation & 36 & 90.00 \\
2 & Can cultivate students' independent creative ability & 39 & 97.50 \\
3 & Can stimulate students' passion for creation & 34 & 85.00 \\
4 & Targeted teaching can be carried out & 38 & 95.00 \\
5 & Promote communication between teachers and students & 37 & 92.50 \\
\hline
\end{tabular}

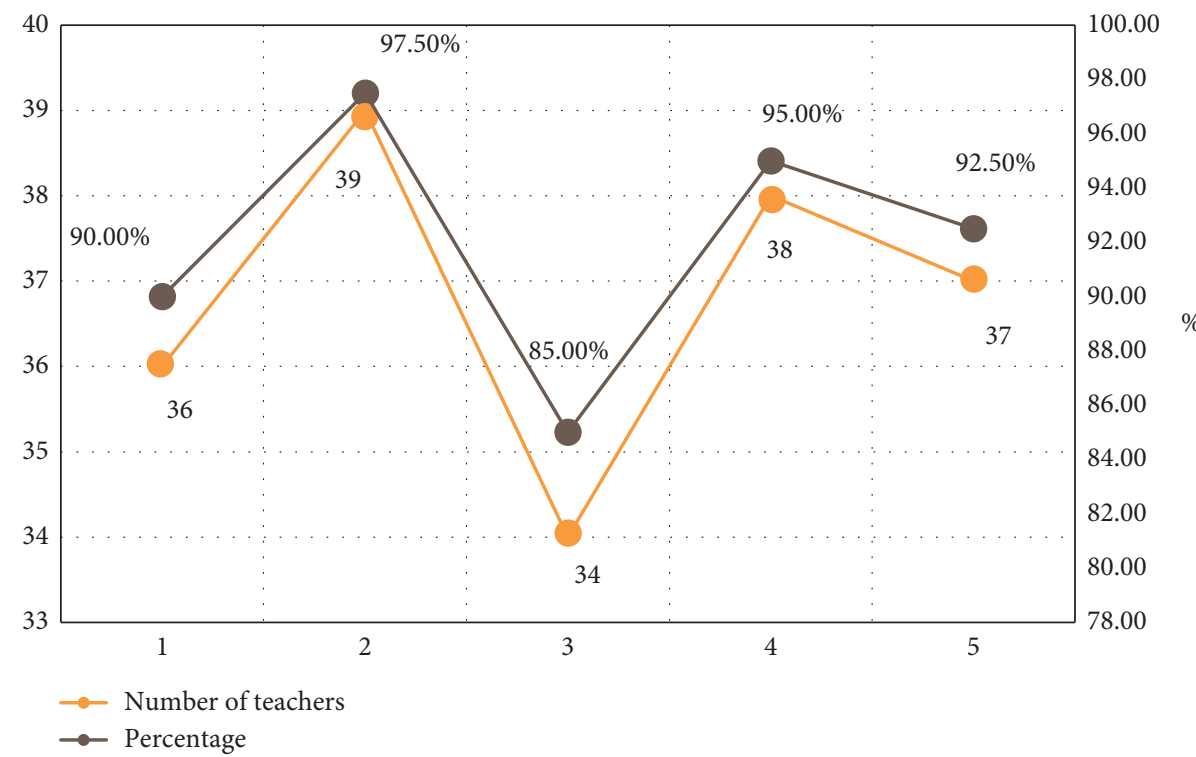

FIgURE 5: Teacher opinion.

unreasonable. The specific situation of the statistical questionnaire validity is drawn into a chart, as shown in Table 6 and Figure 6.
It can be seen from the chart that the scholars who participated in the evaluation affirmed the design, structure, and content of the questionnaire. Most of 
TABLE 6: Questionnaire validity test.

\begin{tabular}{lccccc}
\hline Evaluation standard & Very reasonable & Reasonable & Basically reasonable & Not reasonable & Not reasonable at all \\
\hline Questionnaire structure & 8 & 6 & 7 & 3 & 1 \\
Questionnaire content & 10 & 9 & 4 & 2 & 0 \\
Questionnaire logic & 9 & 11 & 3 & 1 & 1 \\
Questionnaire design & 7 & 13 & 4 & 1 \\
\hline
\end{tabular}

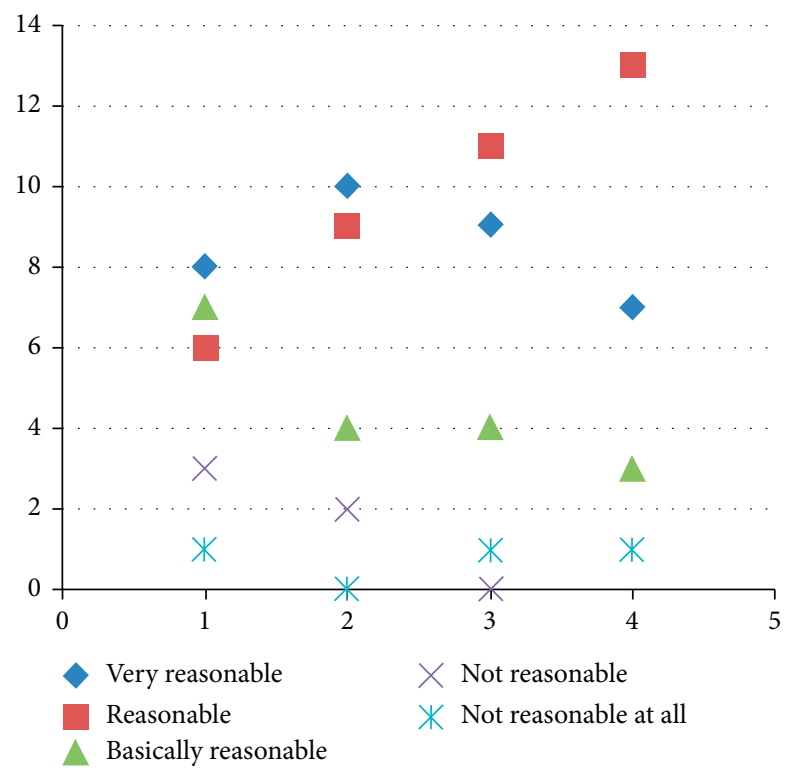

Figure 6: Questionnaire validity test.

TABle 7: Cronbach's $\alpha$ coefficient values.

\begin{tabular}{lccc}
\hline Variable & Dimension composition & $\alpha$ coefficient of each variable & Global $\alpha$ coefficient \\
\hline \multirow{2}{*}{ Students } & Innovation motivation & 0.813 & 0.826 \\
& Innovation quality & 0.834 & 0.820 \\
\multirow{2}{*}{ Teachers } & Quality of teachers & 0.852 & 0.875 \\
& Content of courses & 0.905 & \multirow{2}{*}{0.854} \\
\multirow{2}{*}{ Environmental science } & Teaching method & 0.887 & \multirow{2}{*}{0.896} \\
& Physical environment & 0.864 & 0.856 \\
\multirow{2}{*}{ Teaching quality } & Cultural environment & 0.847 & \multirow{2}{*}{0} \\
\hline
\end{tabular}

the ratings are roughly appropriate and above. Therefore, it can be considered that the validity of this questionnaire is high and it has certain investigation value.

(4) The commonly used reliability test method is the $\alpha$ (Cronbach's alpha) coefficient. In general, the value of Cronbach's $\alpha$ coefficient is between 0 and 1 . The larger the value of $\alpha$, the higher the reliability of the measurement and the better the internal consistency of the scale. If the value of Cronbach's $\alpha$ is above 0.8 , in the survey scale, there is a high internal consistency. An $\alpha$ value between 0.7 and 0.8 indicates that the reliability of the survey scale is within the acceptable range; an $\alpha$ value less than 0.7 indicates that there is a big problem in the design of the measurement scale and it needs to be redesigned. The value of Cronbach's $\alpha$ coefficient in this questionnaire is shown in Table 7 .

The reliability analysis results of each measurement item show that Cronbach's $\alpha$ coefficients are all greater than 0.8 , reaching an acceptable level, indicating that the reliability of the questionnaire is high, and the survey content of the questionnaire is more authentic and reliable.

\section{Conclusions}

Entrepreneurship education is an education model that adapts to the development of the knowledge economy era 
with the birth of Internet high-tech. Its deep level is closely related to employment issues. At present, the state vigorously advocates persisting in innovation-driven, promoting transformational development, and encouraging students to start their own businesses independently is an important way to relieve employment pressure and resolve employment contradictions. It is not only related to the vital interests of students, but also related to the direction of broadening employment.

The core content of the student entrepreneurship course is to cultivate students' innovation ability, innovation, and entrepreneurial skills. Innovation is the foundation of entrepreneurship, and entrepreneurship is the carrier of innovation. The integration of professional knowledge and innovation and entrepreneurial knowledge can cultivate high-quality innovative talents and at the same time focus on theory and practice. Entrepreneurship education system is a new trend of current development. It deepens the need for the reform of the education system of colleges and universities and improves students' performance and enthusiasm.

Intelligent information collection production is an innovative and entrepreneurial practice education model. Through on-site teaching and simulated entrepreneurship teaching, it promotes students' interest in learning and entrepreneurship and employment knowledge, thereby effectively motivating students to learn and promoting good communication between teachers and students. This will optimize the teaching effect and send more professionals and outstanding talents to the animation and digital media industry.

\section{Data Availability}

Data sharing is not applicable to this article as no datasets were generated or analyzed during the current study.

\section{Conflicts of Interest}

These are no potential conflicts of interest in this study.

\section{Acknowledgments}

This work was supported by the Undergraduate Teaching Reform Project of Guangxi Higher Education (2021JGA347), Guilin University of Aerospace Technology's Teaching Reform Project (2021JA03), and Fundamental Ability Enhancement Project for Young and Middle-Aged University Teachers in Guangxi Province (2020KY21029).

\section{References}

[1] W. Wang, "Role of studio system in basic teaching of design disciplines based on evaluation model," Revista de la Facultad de Ingenieria, vol. 32, no. 11, pp. 853-857, 2017.

[2] Z. Zhou, "Research on model construction of innovation and entrepreneurship education in domestic colleges," Creative Education, vol. 7, no. 4, pp. 655-659, 2016.

[3] A. Clarke and S. Hulbert, "Envisioning the future: Working toward sustainability in fine art education," International
Journal of Art \& Design Education, vol. 35, no. 1, pp. 36-50, 2016.

[4] D. Kato, K. Muto, and H. Mitsumine, "The development of the virtual studio system using hybrid sensor," Journal of the Institute of Image Information and Television Engineers, vol. 72, no. 1, pp. J13-J22, 2018.

[5] G. Kelly, "Independent stardom: Freelance women in the hollywood studio system," Historical Journal of Film, Radio and Television, vol. 38, no. 2, pp. 428-430, 2018.

[6] J. R. Hollyfield, "An American kipling: Colonial discourse, settler culture, and the hollywood studio system in George Stevens' Gunga Din," Journal of Commonwealth and Postcolonial Studies, vol. 5, no. 2, pp. 65-77, 2017.

[7] D. Qian, "Visualization analysis and application research of the architectural animation based on digital media technology," Agro Food Industry Hi-Tech, vol. 28, no. 1, pp. 1597$1602,2017$.

[8] R. Mills, L. Tomas, and B. Lewthwaite, "The impact of studentconstructed animation on Middle school students' learning about plate tectonics," Journal of Science Education and Technology, vol. 28, no. 2, pp. 165-177, 2019.

[9] A. Schmitz, D. Urbano, M. Guerrero, and G. A. Dandolini, "Activities related to innovation and entrepreneurship in the academic setting: a literature review," Innovation, Technology, and Knowledge Management, vol. 13, no. 2, pp. 1-17, 2016.

[10] C. Y. Yoomi, "A study on the media art education program applied tangible interface -focused on the free semester of middle school," The Korean Journal of animation, vol. 12, no. 1, pp. 161-182, 2016.

[11] R. Mudaly, K. P. Morgan, L. V. Laren, S. Singh, and C. Mitchell, "Connecting with pre-service teachers' perspectives on the use of digital technologies and social media to teach socially relevant science," Perspectives in Education, vol. 33, no. 4, pp. 23-41, 2015.

[12] O. Samanci, "Embodied site-specific animation," Convergence, vol. 20, no. 1, pp. 14-24, 2016.

[13] S. Czarniewski, "Small and medium-sized enterprises in the context of innovation and entrepreneurship in the economy," Polish Journal of Management Studies, vol. 13, no. 1, pp. 3039, 2016.

[14] F. Gerardo Barroso-Tanoira and F. G. B. Tanoira, "Motivation for increasing creativity, innovation and entrepreneurship. An experience from the classroom to business firms," Journal of Innovation Management, vol. 5, no. 3, pp. 55-74, 2017.

[15] S. Bhagavatula, R. Mudambi, and J. P. Murmann, "Management and organization review special issue 'the innovation and entrepreneurship ecosystem in India', Management \& Organization Review, vol. 13, no. 01, pp. 209-212, 2017.

[16] A. C Michael, "The puzzle of Japanese innovation and entrepreneurship," Communications of the ACM, vol. 59, no. 10, pp. 18-20, 2016.

[17] M. A. Cusumano, "The puzzle of Japanese innovation and entrepreneurship," Communications of the ACM, vol. 59, no. 10, pp. 18-20, 2016.

[18] Y. Yang, "Teaching research on higher vocational pre-school education of professional art course based on innovation and entrepreneurship education," Creative Education, vol. 9, no. 5, pp. 713-718, 2018.

[19] Y. Wang, "Construction elements and path of practical education model in universities," Eurasia Journal of Mathematics Science and Technology Education, vol. 13, no. 10, pp. 6775-6782, 2017.

[20] A. Ali, "The 21st century skills of the female students of practical education in the department of kindergartens in 
faculty of education-king Faisal university," Advances in Social Sciences Research Journal, vol. 7, no. 3, pp. 386-402, 2020.

[21] S. Koshita, S. Yamaki, and M. Abe, "Practical education for cultivation of researchers and engineers of signal processing with emphasis on theory and implementation," IEEJ Transactions on Electronics, Information and Systems, vol. 138, no. 4, pp. 287-298, 2018.

[22] Y.-I. Kim, "Exploring the applicability of maker education theory to practical arts education at elementary school," Journal of Korean Practical Arts Education, vol. 24, no. 2, pp. 39-57, 2018.

[23] M. A. Oudat, M. A. Eisha, and M. K. Thiyabat, "Difficulties that Face physical education students in practical courses," Sport Science, vol. 11, no. 2, pp. 59-69, 2018.

[24] N. Y. Chung, "Directions for future practical arts education to prepare for the 4th industrial revolution era," Journal of Korean Practical Arts Education, vol. 23, no. 4, pp. 1-14, 2017.

[25] C. F. G. Farias, I. M. R. Mesquita, and P. A. Hastie, "The Sport Education Model: research update and future avenues for practice and investigation," Revista Portuguesa de Ciências do Desporto, vol. 2016, no. 1, pp. 73-96, 2016.

[26] M. B. Crawford, Z. S. Wilson-Kennedy, G. A. Thomas, S. D. Gilman, and I. M. Warner, "LA-STEM research scholars program: a model for broadening diversity in STEM education," Technology \& Innovation, vol. 19, no. 3, pp. 577-592, 2018.

[27] G. King, N. Thomson, M. Rothstein, S. Kingsnorth, and K. Parker, "Integrating research, clinical care, and education in academic health science centers," Journal of Health, Organisation and Management, vol. 30, no. 7, pp. 1140-1160, 2016.

[28] C. D. Hundhausen, D. M. Olivares, and A. S. Carter, "IDEbased learning analytics for computing education," ACM Transactions on Computing Education, vol. 17, no. 3, pp. 1-26, 2017. 